\title{
OUT-DOOR RADIATION LEVEL MEASUREMENT IN ABEOKUTA, NIGERIA, BY THERMOLUMINESCENT DOSIMETRY
}

\author{
I. P. Farai \\ Department of Physics, University of Ibadan, Ibadan, Nigeria \\ U. E. Vincent \\ Department of Physics and Solar Energy,Bowen University, Iwo, Nigeria
}

(Submitted: 20 October, 2005; Accepted 10 February, 2006)

Abstract

Environmental radiation level and its spatial variability have been investigated at 34 locations in Abeokuta and environs using the technique of thermoluminescent dosimetry (TLD) with LiF phosphor calibrated with $a^{137}$ Cs standard source operating at a Secondary Standard Dosimetry Laboratory (SSDL). The human dose equivalent due to outdoor exposure in the city range between 0.19 and $1.64 \mathrm{mSv}$ per year with a mean of $0.45 \mathrm{mSv} / \mathrm{y}$ and standard deviation of $0.27 \mathrm{mSv} / \mathrm{y}$. OkeSabo area of the city has the least radiation dose rate while Obantoku area has the upper limit. Taking this as the profile of integrated natural background radiation dose rate from all sources in the city and comparing with measurements of terrestrial radiation dose in a previous survey, the mean dose rate from extraterrestrial (cosmic) radiation has been estimated to be about $0.18 \mathrm{mSv} / \mathrm{y}$ in Abeokuta.

Keywords: Environmental radiation, thermoluminescent dosimetry, Abeokuta, outdoor Radiation exposure.

\section{Introduction}

By the nature of his environment, man is constantly exposed to varying amounts of ionizing radiation dose. This is termed natural background radiation to which all other exposures caused by man's activity in the environment are additional. The main components of natural background radiations are extraterrestrial cosmic rays and radiation due to radioactivity of some primordial elements in the earth. Cosmic rays consist of $87 \%$ protons, $12 \%$ a - particles and $1 \%$ heavier nuclei with energies ranging between $10^{\circ} \mathrm{eV}$ to $10^{17} \mathrm{eV}$. When these high energy particles react with the particles of the atmosphere,

many products such as mesons, electrons (particle), photons, protons and neutrons are emitted and in turn produce other secondary particles as they travel down to the earth's surface. Data are very sparse on the intensity of cosmic radiation in our environments.

Radioactivity of the earth is due to the primordial elements ${ }^{238} \mathrm{U},{ }^{232} \mathrm{Th}$ and ${ }^{40} \mathrm{~K}$ with half-lives which are comparable with the age of the earth. Both ${ }^{238} \mathrm{U}$ and ${ }^{232} \mathrm{Th}$ have long decay series with members $\left({ }^{226} \mathrm{Ra},{ }^{222} \mathrm{Rn},{ }^{214} \mathrm{Bi}\right.$, etc. $)$, all of which are radioactive. Natural potassium, an ubiquitous element in the soil, contains $0.0119 \%$ radioactive ${ }^{40} \mathrm{~K}$. Radiations emitted by these elements within $15-30 \mathrm{~cm}$ topsoil reach the earth surface. We also have radioactivity in air due mainly to the presence of radon $\left({ }^{222} \mathrm{Rn}\right)$ and thoron $\left({ }^{220} \mathrm{Rn}\right)$ gases formed as daughter products in the ${ }^{238} \mathrm{U}$ and ${ }^{232} \mathrm{Th}$ series, respectively. They emanate readily from the soil to build up in air at concentrations that depend on meteorological conditions and ventilation in dwelling volumes. The terrestrial component of natural background radiation is therefore strongly influenced by local geology.

In addition to the inevitable natural background radiation sources, man can be exposed to various man-made radiations sources, or natural sources that are enhanced by human activities such as mining. Because of the deleterious health effects of radiation exposure (Hanson and Komorov, 1983), the practice has been to keep exposure to man-made sources to as low as 
reasonably achievable, usually termed the ALARA principle. However, the risks of accidents, which can result in environmental pollution of radioactive substances, are always finite (Gogolak, et al, 1986 and IAEA, 1988). An accurate knowledge of the natural background radiation in an environment is essential for a correct assessment of radiation level due to such pollution.

Some data have been acquired in Nigeria on this (Olomo et al, 1994, Avwiri. and Ebeniro, 2002). The environments and localities yet covered are quite limited. The mean radioactivity concentrations of ${ }^{40} \mathrm{~K},{ }^{238} \mathrm{U}$ and ${ }^{232} \mathrm{Th}$ in the topsoil in Abeokuta and its environs have been measured in a nationwide survey (Farai and Jibiri, 2000) as $799 \pm 295,83 \pm 18$ and $218 \pm 70 \mathrm{~Bq} / \mathrm{kg}$, respectively with the errors being the standard deviation which represent the spatial spread in radioactivity levels. These levels amount to an effective dose equivalent rate of about $273 \mu \mathrm{Sv} / \mathrm{hr}$ compared with the world average of $70 \mu \mathrm{Sv} / \mathrm{hr}$ (UNSCEAR, 1988). This calls for a cursory look at the total dose distribution in this area, which is the objective of the present study with the thermoluminescent dosimetry (TLD) technique of total dose measurement.

\section{Materials and Method \\ Selection of surveyed sites}

The study area consists of Abeokuta and environs with a population of about 500,000 according to 1992 census projected to the time of the present study. The area is amidst a group of granitic rocks of Precambrian formation. The geology of the area is underlain by originalities, mignetitic gneiss and granite gneiss and course porphyritic granite. Mignetitic gneiss rocks cover only very limited areas while granite gneiss cover the most extensive terrain of the area, at the center of which we have the Olumo rocks, a famous tourist center.

\section{Measurement Procedure}

Radiation absorbed dose measurement in this work has been carried out using the facilities of the Secondary Standard Dosimetry Laboratory (SSDL) at the Federal Radiation Protection Service (FRPS) in the Department of Physics,
University of Ibadan. The laboratory is equipped with ${ }^{60} \mathrm{Co}\left(\mathrm{T}_{1 / 2}=5.2 \mathrm{y}\right)$ and ${ }^{137} \mathrm{Cs}\left(\mathrm{T}_{1 / 2}=30 \mathrm{y}\right)$ standard gamma radiation sources with initial activities (in May 1998) of $3.7 \mathrm{GBq}$ and 740 GBq, respectively. It also has a $160-\mathrm{kVp}$ x-ray source as well as laser beam for high precision measurements. A TLD system comprising of LiF cards and a Solaro (Vinteen) Dual Channel TLD reader (Model 680) has been employed. Each TLD card consists of two $0.4 \mathrm{~cm}$ diameter LiF chips. The TLD reader has an in-built computer system to facilitate accurate dose assessment after appropriate calibration and it is programmed to anneal TLD chips automatically for fresh use after each measurement.

\section{Calibration}

Calibration was carried out by irradiating a set of five TLD cards; each consisting of two freshly annealed $\mathrm{LiF}$ chips $\mathrm{A}$ and $\mathrm{B}$, to a standard dose in the ${ }^{137} \mathrm{Cs}$ gamma beam. The dose rate at $1.0 \mathrm{~m}$ from the Cs source at the time of calibration was certificated by the IAEA as $47.91 \pm 0.02 \mathrm{mGy} / \mathrm{hr}$. The standard deviation representing the spread in the TLD response during the calibration exercise was between 1.5 and $5.3 \%$, showing a very good precision. The mean TLD reader output $\mathrm{R}$ for each set was plotted against the standard absorbed dose D (mSv). The calibration lines for chips A and chips B with correlation coefficients 0.9996 and 0.9989 , respectively are shown in Fig. 1 . The lines were fitted with equations:

$R_{A}=101.81 D+10.05$

$R_{B}=40.15 D+10.83$

where $\mathrm{D}$ is the actual radiation dose to which gives response $R_{A}$ in chip $\mathrm{A}$ and $R_{B}$ in chip $\mathrm{B}$.

\section{Measurement}

The TLD detector chips were annealed and exposed at the human gonadal height of about 1 $m$ above the ground in all the 34 sites surveyed. Attempts were made to have an even coverage of the city but the spatial interval between two chips could not be kept constant as this was influenced by many factors such as protection from harsh weather conditions like intense heat, rain and wind, as well as physical 
Table 1: Results of dose rate measurement by TLDS in Abeokuta, Nigeria

\begin{tabular}{|c|c|c|c|c|}
\hline $\begin{array}{l}\text { Location } \\
\text { Code }\end{array}$ & Location & $\begin{array}{c}\text { Absorbed } \\
\text { Dose in } 3 \\
\text { months } \\
(\mathrm{mGy})\end{array}$ & $\begin{array}{l}\text { Absorbed Dose } \\
\text { in one year } \\
(\mathrm{mGy})\end{array}$ & $\begin{array}{c}\text { Annual } \\
\text { Effective } \\
\text { dose (mSv) }\end{array}$ \\
\hline 1 & Obantoko & 2.93 & 11.72 & 1.64 \\
\hline 2 & FCE, Osile & 1.71 & 6.84 & 0.96 \\
\hline 3 & Asero Estate & 0.62 & 2.48 & 0.35 \\
\hline 4 & EHS, Asero & 0.51 & 2.04 & 0.29 \\
\hline 5 & COLNAS, UNAAB & 0.74 & 2.96 & 0.41 \\
\hline 6 & COPLANT, UNAAB & 0.86 & 3.44 & 0.48 \\
\hline 7 & Mokola & 0.36 & 1.44 & 0.20 \\
\hline 8 & Iberekodo & 0.90 & 3.60 & 0.50 \\
\hline 9 & Oke-Saje & 1.04 & 4.16 & 0.58 \\
\hline 10 & Ake & 0.54 & 2.10 & 0.30 \\
\hline 11 & Olorunsogo & 0.69 & 2.76 & 0.39 \\
\hline 12 & Idi-Aba & 0.70 & 2.80 & 0.39 \\
\hline 13 & Ogbe & 0.55 & 2.20 & 0.31 \\
\hline 14 & Aro & 1.34 & 5.36 & 0.75 \\
\hline 15 & Oke-Sokori & 0.66 & 2.64 & 0.37 \\
\hline 16 & Onikolobo & 0.94 & 3.76 & 0.53 \\
\hline 17 & Isabo & 0.55 & 2.20 & 0.31 \\
\hline 18 & Kuto & 0.41 & 1.64 & 0.23 \\
\hline 19 & Amolaso Hill (1) & 1.59 & 6.36 & 0.89 \\
\hline 20 & Amolaso Hill (2) & 0.74 & 2.96 & 0.41 \\
\hline 21 & Isabo & 0.76 & 3.04 & 0.43 \\
\hline 22 & UNAAB Mini Compus & 0.58 & 2.32 & 0.33 \\
\hline 23 & Ago-Oko & 0.87 & 3.48 & 0.49 \\
\hline 24 & Ijeun-Titun & 0.74 & 2.96 & 0.41 \\
\hline 25 & ljaye & 0.72 & 2.88 & 0.40 \\
\hline 26 & Quarry Road & 0.70 & 2.80 & 0.39 \\
\hline 27 & Oke-Sabo & 0.34 & 1.36 & 0.19 \\
\hline 28 & Sabo (Agbo-Eran & 0.76 & 3.04 & 0.43 \\
\hline 29 & Lafenwa (Barracks) & 0.49 & 1.96 & 0.27 \\
\hline 30 & Gaa Area 1 & 0.56 & 2.24 & 0.31 \\
\hline 31 & Gaa Area 2 & 0.65 & 2.60 & 0.36 \\
\hline 32 & Ayetoro Road 1 & 0.55 & 2.20 & 0.31 \\
\hline 33 & Ayetoro Road 2 & 0.58 & 2.32 & 0.31 \\
\hline 34 & GRA Ibara & 0.91 & 3.64 & 0.51 \\
\hline
\end{tabular}




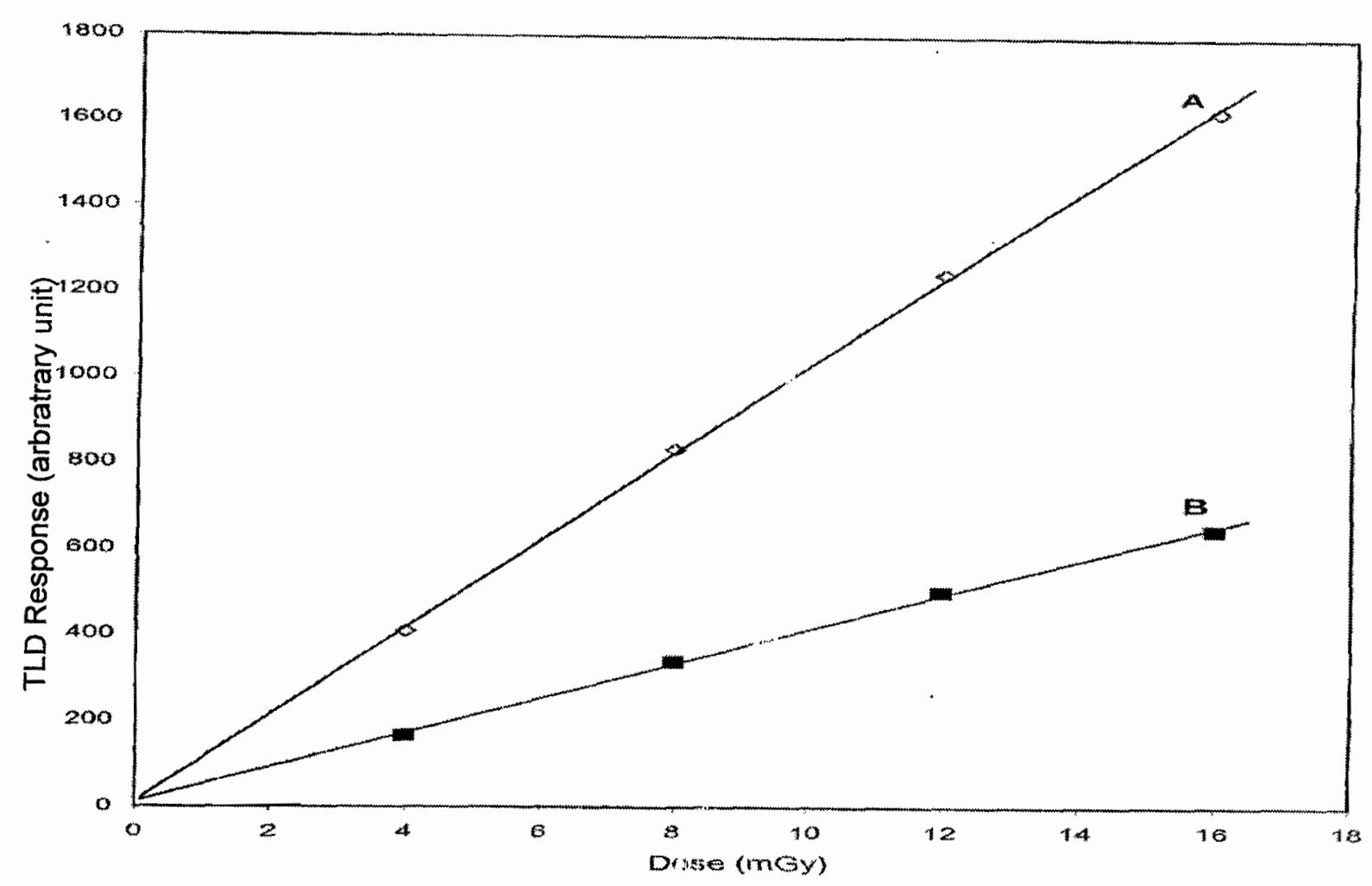

Fig. 1: Calibration curves for chips A and B

protection from vandalisation. The detector chips were exposed for a period of 3 months after which they were collected from ine locations and read in the laboratory with the calibrated TLD system. The absorbed dose ') at a location was calculated as the mean the slightly varying dose values obtaine $e^{\prime}$. from chips $A$ and $B$ using equations 1 and 2 .

\section{Results and Discussion}

The results for the 34 sites investi ated are presented Table 1 . The absorbed dos $(\mathrm{mGy})$ in three months is given in the third col mn of the table. This has been projected to ann tal dose in the fourth column. In order to asses the biological effects on man, the vall is must be converted to human effective dose equivalent $(\mathrm{mSv} / \mathrm{y})$. The United Nations Scientific Committee on the Effects of Atomic Radiation (UNSCEAR, 1988) has recommended $0.7 \mathrm{~Sv} / \mathrm{Gy}$ as the value to convert the absorbed dose rate in air to human equivalent dose rate. It has also recommended 0.2 as the outdoor occupancy factor which gives the proportion of the total time which an individual is exposed to radiation field outdoor. By using these two factors, the outdoor annual effective dose equivalent has been calculated and presented in the fifth column of Table 1 . The values range from 0.19 to $1.64 \mathrm{mSv} / \mathrm{y}$ with a mean and standard deviation of 0.45 and $0.27 \mathrm{mSv} / \mathrm{y}$, respectively.The mean value effective dose equivalent due to terrestrial radiation obtained for the area in an earlier nationwide survey (Farai and Jibiri, .2000) by the technique of in-situ gamma radiation measurement is $0.27 \mathrm{mSv} / \mathrm{y}$. The present value of $0.45 \mathrm{mSv} / \mathrm{y}$ with the technique of Thermoluminescent Dosimetry (TLD) agrees with the earlier result if we bear in mind that the TLD technique integrates both terrestrial and extra terrestrial (cosmic) radiations. The combination of the two results provides a ready means of assessing the cosmic radiation component of natural background radiation in the city of Abeokuta. An estimate of the average cosmic radiation level in the city will therefore be about $0.18 \mathrm{mSv} / \mathrm{y}$.

The distribution of the background radiation level in Abeokuta is clearly depicted by the bar chart in Fig.2. 


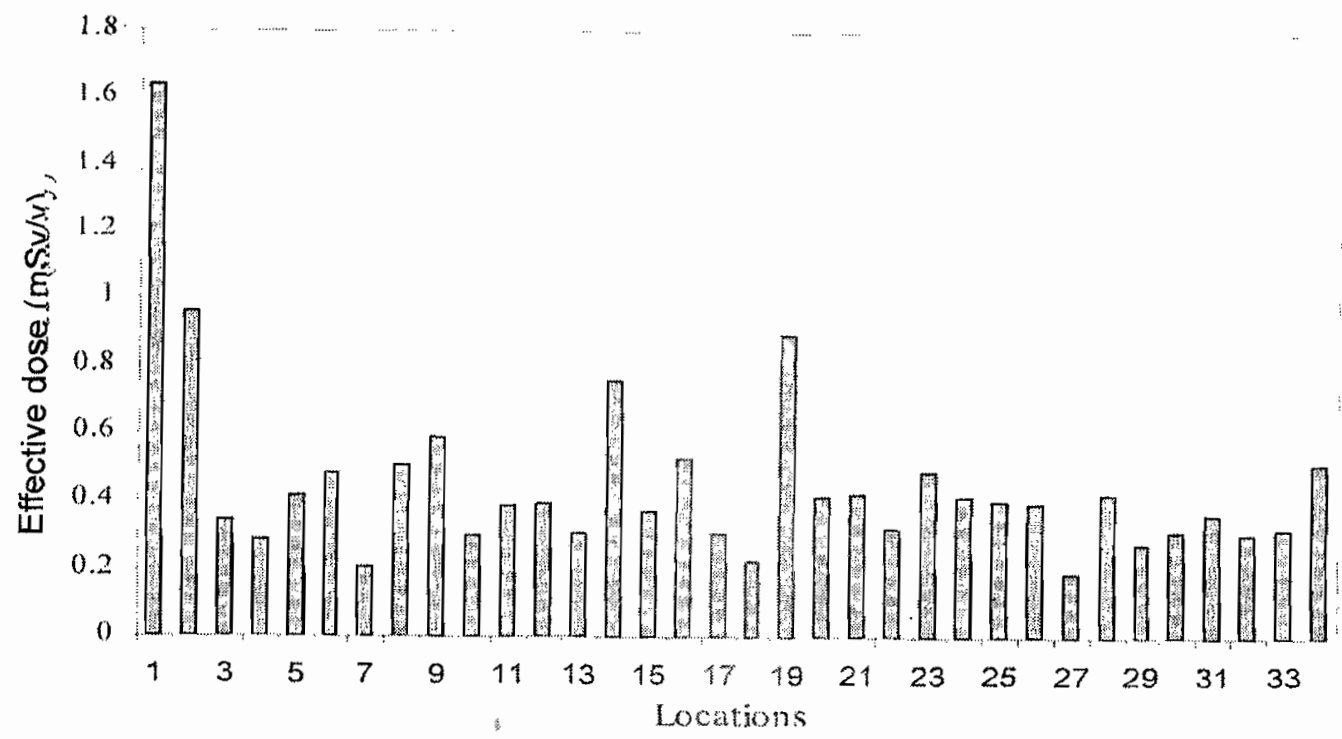

Fig. 2: Distribution of human outdoor effective dose (mSv/y) in Abeokuta

The wide spread ( 0.19 to $1.64 \mathrm{mSv} / \mathrm{y})$ shows the spatial variation in the natural radiation level within the city. Of a striking importance is the agreement of the elevated value radiation level in Obantoku area with measurement of radioactivity in building blocks in a recent survey by Ademola (2003) and Farai and Ademola (2005). The radium equivalent of 21 building block samples collected from the city ranged between 90 and $446 \mathrm{~Bq} / \mathrm{kg}$ with those from Obantoku area being at the upper limit, which exceeds the maximum permissible limit of $370 \mathrm{~Bq} / \mathrm{kg}$ (UNSCEAR, 1982). From gamma spectrometric analysis of the materials, it was observed that the concentration of natural Th-232 is quite high (up to $241.41 \pm$ $38.35 \mathrm{~Bq} / \mathrm{kg}$ ) in the area. This clearly explains the high radiation level in this area. Further investigation is suggested for this particular neighbourhood.

\section{Conclusion}

Total outdoor radiation exposure has been measured in the city of Abeokuta and its environs with the technique of thermoluminescent dosimetry. The human

\section{References}

Ademola, J.A (2003): Radiation Dose from Concrete Building Blocks in Eight Cities of Southwestern Nigeria. A Ph.D Thesis, University of Ibadan, Ibadan. dose equivalent in the city range between 0.19 and $1.64 \mathrm{mSv}$ per year with a mean of 0.45 $\mathrm{mSv} / \mathrm{y}$ and standard deviation of $0.27 \mathrm{mSv} / \mathrm{y}$. The standard deviation represents the spatial spread in radiation level distribution, which is fairly large. Oke-Sabo area of the city has the least radiation dose rate while Obantoku area has the upper limit. This result is consistent with recent measurements which identifies Obantoku as an area with elevated radiation level zone. Comparing results with data on terrestrial radiation level in the area, it has been possible to estimate the extraterrestrial component of natural background radiation in the area to be about $0.18 \mathrm{mSv} / \mathrm{y}$. These results provide the essential baseline information for the assessment of any environmental radioactivity contamination of the area in the foreseeable future.

\section{Acknowldgement}

The authors are grateful to Dr. Rachael Obed of the Department of Physics, University of Ibadan, for her assistance during the calibration exercise and also to the technical staff of the FRPS for all the needed assistance rendered.

Avwiri, G: O. and Ebeniro, J. O. (2002): A Survey of The Background Radiation Levels of the Sub-Industrial Areas of Port Harcourt. Global J. Pure and Appli. Sci. 8(1): 111- 113. 
Farai, I. P and Jibiri, N. N. (2000): Baseline studies of Terrestrial outdoor gamma dose rate levels, in Nigeria. Radiat. Prot. Dosim. 88(3) 247- 254.

Farai, I.P and Ademola, J.A (2005): Radium Equivalent Activity Concentrations in Concrete Building Blocks in Eight Cities in Southwestern Nigeria Journal of Environmental Radioactivity 79 119- 125 .

Gogolak, C.W, Winkelman, I., Weiner, S., Wolf, S. and Klopfer, P. (1986): Observation of Chernobyl Fallout in Germany by In Situ Gamma Spectrometry, USDOE Report EML 460.

Hanson, G. P. and Komorov, E. (1983): Health Effects in residents of high background regions. In: Biological Effects of low Level Radiations. Proceeding of Symposium Venice, IAEA, Vienna

IAEA, (1988): International Atomic Energy Agency. The Radiological Accident in
Goiania ST1/PUB/815(Vienna:IAEA)

ICRP (1991): The 1990 - 1991 Recommendations of the International Commission on Radiological Protection. Publication 60. Ann. ICRP 21, (1-3), Pergamon Press; Elmsford, NY.

Olomo, J. B., Akinloye, M.K. and Balogun, F.A. (1994): Distribution of GammaEmitting Natural Radionuclides in Soils and Water around Nuclear Research Establishments: Ile-Ife, Nigeria. Nucl. Instr. And Meth. A353, 553-557.

UNSCEAR (1982): Ionizing Radiation: Sources and Biological Effects United Nations Scientific Committee on the Effects of Atomic Radiation. A Report to the General Assembly with Annexes (New York: UN).

UNSCEAR. (1988): Ionizing Radiation: Sources and Biological Effects United Nations Scientific Committee on the Effects of Atomic Radiation. A Report to the General Assembly (New York: UN). 